\title{
PERENCANAAN PEMBANGKIT LISTRIK TENAGA MIKROHIDRO DI BENDUNGAN SEMANTOK, NGANJUK, JAWA TIMUR
}

\author{
Faris Azhar, Abdullah Hidayat, Edijatno \\ Jurusan Teknik Sipil, Fakultas Teknik Sipil dan Perencanaan, Institut Teknologi Sepuluh Nopember (ITS) \\ Jl. Arief Rahman Hakim, Surabaya 60111 Indonesia
}

\begin{abstract}
Abstrak- Penerapan teknologi mikrohidro sebagai pembangkit listrik merupakan solusi yang tepat untuk memanfaatkan potensi perbedaan muka air antara hulu dan hilir bendungan. Pembangkit Listrik Tenaga Mikrohidro dapat dibangun dengan syarat perbedaan ketinggian minimal 2 meter dan debit selalu tersedia, karena yang digunakan hanya energi potensialnya, sehingga debit air masih dapat dimanfaatkan untuk pengairan.

Di Kali Semantok yang terletak di Desa Sambikerep, Kecamatan Rejoso, Kabupaten Nganjuk, Jawa Timur direncanakan sebuah bendungan yang mempunyai beda elevasi total setinggi 20,34 dan debit minimum 0,02m3/detik sehingga dapat dimanfaatkan sebagai Pembangkit Listrik Tenaga Mikrohidro (PLTMH).

Dengan memanfaatkan debit kebutuhan irigasi Daerah Irigasi Bendungan Semantok sebesar debit rencana 0,20 m3/detik, 0,40 m3/detik, 0,60 m3/detik, dan tinggi jatuh efektif berkisar antara 24,00 - 26,35 meter, serta menggunakan turbin Kaplan maka perbedaan beda ketinggian muka air pada hulu dan hilir Bendungan Semantok menghasilkan daya listrik sebesar 3.407,79 Kw dan energi listrik per tahun sebesar 827.534,01 kWh.
\end{abstract}

Kata Kunci-Mikrohidro, debit rencana, debit kebutuhan irigasi, ketinggian efektif, energi listrik

\section{PENDAHULUAN}

Pada Kali Semantok Desa Sambikerep, Kecamatan Rejoso, Kabupaten Nganjuk, Jawa timur direncanakan waduk yang berfungsi untuk irigasi dan pengendalian banjir. Kali Semantok mempunyai luas DAS sebesar $14,29 \mathrm{~km}$ dan dengan debit rata-rata tahunan sebesar $0,53 \mathrm{~m} / \mathrm{dt}$. Volume tampungan waduk direncanakan sebesar 5,60 juta $\mathrm{m}$, dengan kapasitas tampungan efektif sebesar 4,17 juta $m$ dan kapasitas tampungan mati sebesar 1,43 juta m. Selain berfungsi untuk irigasi dan pengendalian banjir, bendungan Semantok memanfaatkan keluaran air sebagai pembangkit listrik tenaga air.

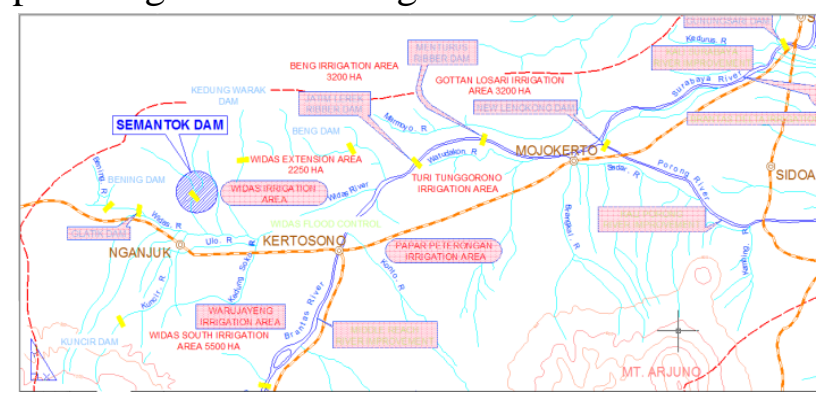

Gambar 1. Peta Sungai Widas dan Bendungan Semantok di Kab. Nganjuk

Potensi air yang dilepas pada bendungan ini dapat digunakan untuk Pembangkit Listrik

Tenaga Air (PLTA) dengan memutar turbin yang selanjutnya dari putaran itu dikonversikan oleh generator menjadi energi listrik. Dengan adanya PLTA ini diharapkan mampu memberikan tambahan kontribusi energi listrik guna memenuhi kebutuhan energi listrik di wilayah setempat.

\section{METODOLOGI}

Metodologi Tugas Akhir ini dapat dilihat pada Gambar 2. 


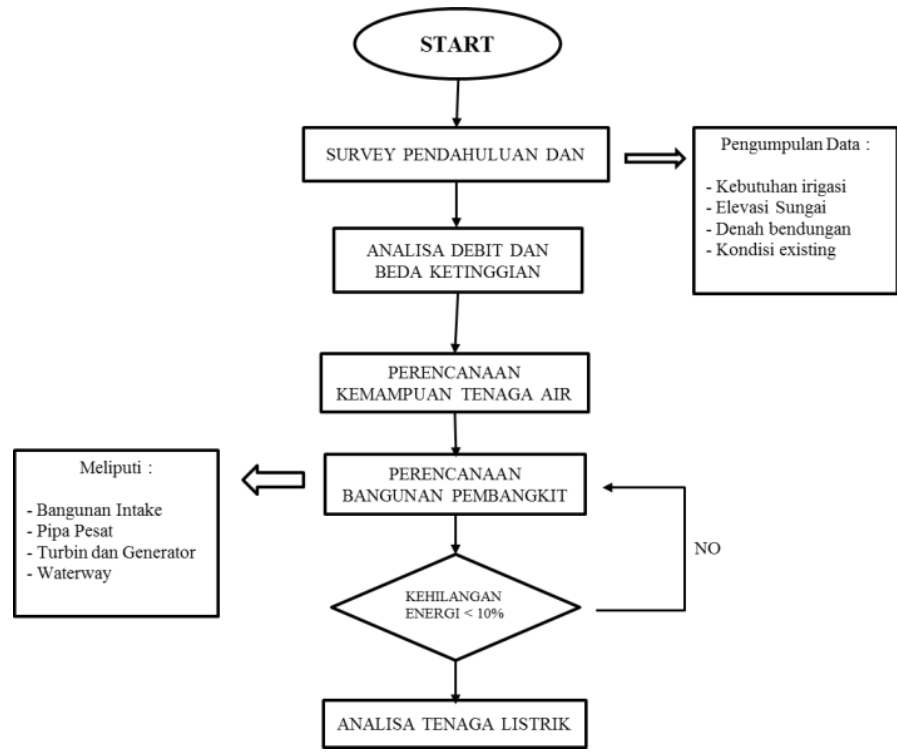

Gambar 2. Diagram Alir Metodologi Tugas Akhir

\section{HASIL DAN PEMBAHASAN}

\section{A. Analisa Data}

Debit rencana yang akan dimanfaatkan sebagai inflow pembangkit listrik adalah debit kebutuhan irigasi daerah irigasi bendungan Semantok yang terbagi menjadi 3 (tiga) periode yaitu periode rendah $\left(0,20 \mathrm{~m}^{3} / \mathrm{dt}\right)$, periode sedang $\left(0,40 \mathrm{~m}^{3} / \mathrm{dt}\right)$, dan periode tinggi $\left(0,60 \mathrm{~m}^{3} / \mathrm{dt}\right)$.

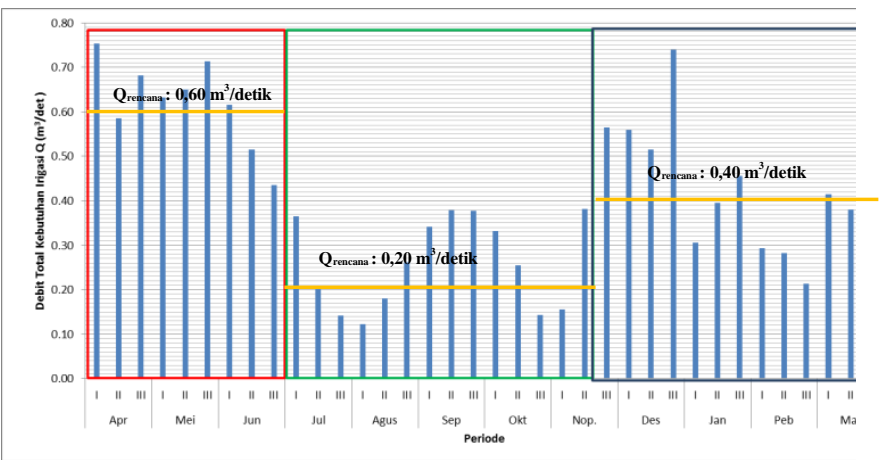

\section{Gambar 3. Pembagian Debit Rencana inflow PLTA}

\section{B. Perhitungan Tinggi Jatuh Efektif}

Tinggi jatuh efektif diperoleh dengan mengurangi tinggi jatuh air yang ada di lapangan dengan kehilangan tinggi akibat saluran air. Dalam perencanaan awal akan diambil kehilangan energi sebesar 10\% dari tinggi bruto. $\mathrm{H}_{\text {eff }}=\mathrm{H}_{\text {bruto }}-\mathrm{H}_{\text {losses }}[1]$

Hal 2
$\mathrm{H}_{\text {bruto }}$ didapat dari selisih antara elevasi muka air pada Upstream bendungan, dengan elevasi di rumah turbin, dalam perencanaan ini elevasi rumah turbin diletakkan pada elevasi $+100 \mathrm{~m}$. Berikut contoh perhitungan tinggi efektif $\left(\mathrm{H}_{\mathrm{eff}}\right)$ pada saat muka air normal (N.W.L: $+127,75 \mathrm{~m}$ ).

$\mathrm{H}_{\text {eff }}=\mathrm{H}_{\text {bruto }}-\mathrm{H}_{\text {losses }}$ dimana:

$\mathrm{H}_{\text {bruto }} \quad=$ Elevasi Muka Air Normal (N.W.L) - Elevasi Downstream

$=+127,75 \mathrm{~m}-+100,00 \mathrm{~m}$

$=27,75 \mathrm{~m}$

$\mathrm{H}_{\text {losses }}=10 \% \times \mathrm{H}_{\text {bruto }}$

$=10 \% \times 27,75 \mathrm{~m}$

$=2,77 \mathrm{~m}$

\section{Perencanaan Bangunan Pembangkit}

\section{Perencanaan Intake}

Bangunan intake berfungsi sebagai tempat pemasukan debit rencana ke dalam pipa pesat yang kemudian dialirkan ke turbin yang mengubah energi kinetik menjadi energi listrik, maupun ke dalam waterway yang berfungi sebagai pemenuh kebutuhan air untuk irigasi. Bangunan intake pada perencanaan ini menggunakan free intake yang terletak di sebelah kanan bendungan. Bangunan free intake tersebut berbentuk shaft tegak dari elevasi +119.00 meter sampai elevasi +96.40 meter $(\mathrm{H}=$ 22,60 meter).

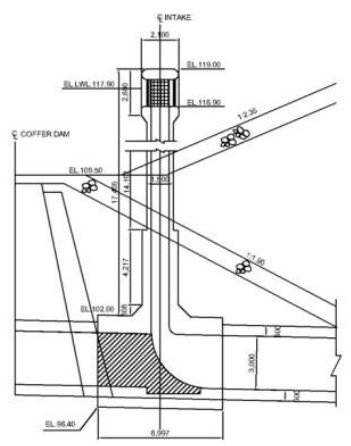

\section{Gambar 4. Bangunan Free Intake}

Pada bangunan intake dipasang trashrack yang berfungsi sebagai penyaring agar air yang masuk ke dalam saluran terbebas dari sampah, batang 
Perencanaan Pembangkit Listrik Tenaga Mikrohidro di Bendungan Semantok, Nganjuk, Jawa Timur

kayu ataupun benda-benda yang dapat mengganggu aliran.

\section{Perencanaan Diameter Pipa Pesat}

Untuk menghitung diameter pipa pesat digunakan perumusan USBR. Dari perumusan USBR didapat bahwa kecepatan air yang melalui pipa pesat adalah:

$\mathrm{V}=0,125 \sqrt{2 g H_{\text {eff }}}[1]$

Dalam perhitungan kecepatan ini, ketinggian efektif diambil pada saat elevasi air rendah (Low Water Level) yaitu pada saat elevasi $+117,90 \mathrm{~m}$, sehingga ketinggian efektif $=16$ meter .

Sehingga kecepatan aliran dalam pipa pesat pada saat elevasi muka air rendah adalah:

$\mathrm{V}=0,125 \sqrt{2 \times 9,81 \times 16}$

$=2,21 \mathrm{~m} /$ detik

dimana:

$$
\begin{array}{lr}
\mathrm{V} & =\text { kecepatan aliran }(\mathrm{m} / \text { detik }) \\
\mathrm{g} & =\text { percepatan gravitasi }\left(\mathrm{m} / \mathrm{dt}^{2}\right) \\
\mathrm{H}_{\mathrm{eff}} & =\text { tinggi jatuh efektif }(\mathrm{m})
\end{array}
$$

Kecepatan dalam pipa pesat diambil nilai $2-3$ $\mathrm{m} /$ detik. Sehingga dari perhitungan kecepatan dalam pipa pesat di atas memenuhi syarat. Hasil perhitungan kecepatan dalam pipa pesat digunakan dalam perhitungan diameter pipa pesat seperti berikut:

$\mathrm{D}=\sqrt{\frac{Q_{\text {rencana }}}{0,25 \pi v}}$

$\mathrm{D}=\sqrt{\frac{0,20}{0,25 \pi 2,21}}=0,339 \sim 0,35 \mathrm{~m}$

\section{dimana:}

D = diameter pipa pesat USBR

$\mathrm{Q}_{\text {rencana }}=$ debit rencana minimum $(0,20$

$\mathrm{m}^{3} /$ detik)

$\mathrm{V}=$ kecepatan aliran $(\mathrm{m} /$ detik $)$

Nilai diameter pipa baja yang didapat dikontrol dengan kecepatan aliran pipa pesat yang terjadi:

$\mathrm{V}=\frac{Q}{A}=\frac{Q}{0,25 x \pi x D^{2}}$

$\mathrm{V}=\frac{Q}{A}=\frac{0,20}{0,25 \times \pi \times 0,35^{2}}=2,07 \mathrm{~m} / \mathrm{detik}$
Dari hasil kontrol diameter pipa dengan kecepatan, didapat kecepatan pipa pesat sebesar 2,07 $\mathrm{m} /$ detik. Nilai ini masih dalam batas kecepatan pipa pesat, yaitu antara $2-3$ $\mathrm{m} / \operatorname{detik}[1]$

\section{Perencanaan Waterway}

Dalam perencanaan ini waterway berfungsi sebagai pemenuhan kekurangan kebutuhan debit irigasi yang lewat melalui pipa pesat. Dalam perencanaan ini waterway didesain dalam bentuk bujur sangkar. Sehingga lebar (b) waterway sama dengan tinggi (h) waterway. Dalam perencanaan ini, debit maksimal yang melalui waterway sebesar $0,35 \mathrm{~m}^{3} /$ detik. sehingga perhitungan dimensi waterway adalah sebagai berikut:

$$
\begin{array}{ll}
\mathrm{Q} & =\mathrm{v} \times \mathrm{A}[2] \\
\mathrm{A} & =\mathrm{b} \times \mathrm{h} \\
\mathrm{A} & =\mathrm{h}^{2}
\end{array}
$$

Sehingga:

$$
\begin{array}{ll}
\mathrm{Q} & =\mathrm{v} \mathrm{x} \mathrm{h}^{2} \\
0,35 & =0,5 \mathrm{x} \mathrm{h}^{2} \\
\mathrm{~h}^{2} & =0,7 \\
\mathrm{~h} & =\sqrt{0,7}
\end{array}
$$

$\mathrm{h}=0,836$ meter $\sim 0,85$ meter,

karena waterway berbentuk bujur sangkar, maka lebar waterway sama dengan tingginya yaitu 0,85 meter

dimana:

$\mathrm{Q}=$ selisih debit rencana dan kebutuhan irigasi

$\mathrm{v}=$ kecepatan aliran dalam waterway $(0,5 \mathrm{~m} / \mathrm{dt})$

$\mathrm{A}=$ luas penampang saluran

\section{Perencanaan Turbin}

Pada saat merencanakan jenis turbin, faktor yang paling menentukan adalah besar debit dan beda tinggi yang tersedia. Pada perencanaan ini debit rencana sebesar $0,20 \mathrm{~m}^{3} /$ detik dan tinggi jatuh efektif sebesar 16 meter, dengan melihat grafik pemilihan jenis turbin, maka jenis turbin yang efektif digunakan adalah turbin jenis Kaplan yang memiliki spesifikasi dengan tinggi jatuh efektif 3 - 60 meter dan debit $0-50.000$ liter/detik. 
$\mathrm{g}$ = gravitasi bumi, diambil $9,81 \mathrm{~m} / \mathrm{dt}^{2}$

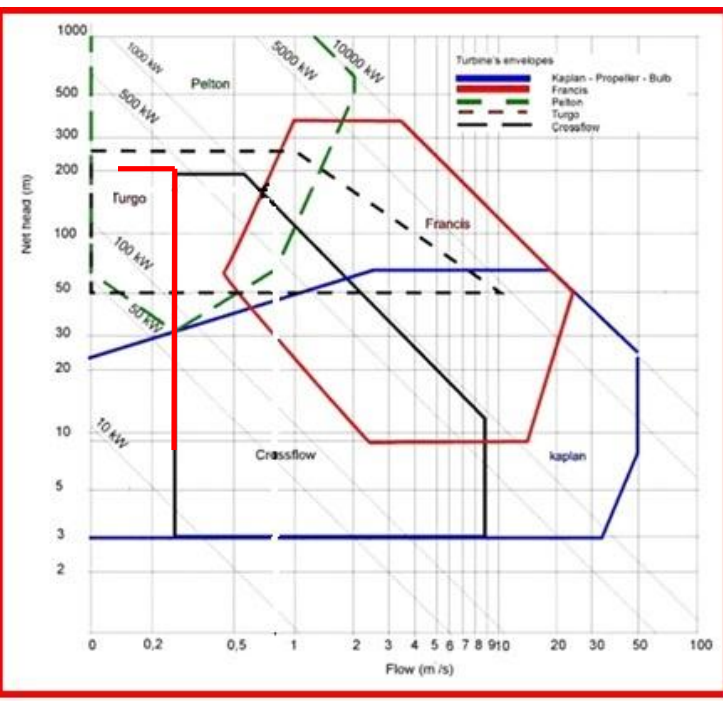

\section{Gambar 5. Grafik Pemilihan Jenis Turbin}

\section{E. Estimasi Kehilangan Energi}

Kehilangan Energi karena Saringan Kasar

Untuk menghitung kehilangan energi yang terjadi, digunakan perumusan sebagai berikut:

$\mathrm{h}_{\mathrm{r}}=\varphi\left(\frac{s}{b}\right)^{\frac{4}{3}} \frac{\Delta V^{2}}{2 g} \sin \alpha[1]$

$=0,76\left(\frac{0,02}{0,10}\right)^{\frac{4}{3}} \frac{2,21^{2}}{2 \cdot 9,81} \sin 90^{\circ}$

$=0,108075 \mathrm{~m}$

\section{dimana:}

$\mathrm{hr}=$ kehilangan energi saringan pipa $(\mathrm{m})$

$\varphi=$ koefisien profil $(0,76)$

$\mathrm{S}=$ lebar profil dari arah aliran $(0,02 \mathrm{~m})$

$\mathrm{b}=$ jarak antar profil saringan $(0,10 \mathrm{~m})$

$\mathrm{g}=$ gravitasi bumi, diambil $9,81 \mathrm{~m} / \mathrm{dt}^{2}$

$\alpha=$ sudut kemiringan saringan $\left(60^{\circ}\right)$

$\mathrm{v}=2,21 \mathrm{~m} / \mathrm{dt}$

Kehilangan Energi pada Entrance Pipa Pesat

$$
\begin{aligned}
& \mathrm{H}_{\mathrm{e}}=\mathrm{K}_{\mathrm{e}} \cdot\left(\frac{\Delta V^{2}}{2 g}\right)[1] \\
& \mathrm{H}_{\mathrm{e}}=0,05 \cdot\left(\frac{2,21^{2}}{2 \times 9,81}\right) \\
& \mathrm{H}_{\mathrm{e}}=0,012447
\end{aligned}
$$

dimana:

$\mathrm{He}=$ kehilangan energi pada entrance $(\mathrm{m})$

$\mathrm{Ke}=$ koefisien bentuk mulut entrance $(0,05)$

$\Delta \mathrm{v}=$ selisih kecepatan sebelum dan sesudah entrance $(\mathrm{m} / \mathrm{dt})$

Hal 4
Kehilangan Energi Akibat Gesekan Sepanjang Pipa

$\mathrm{H}_{\mathrm{f}} \quad=f \cdot \frac{L}{D} \cdot \frac{v^{2}}{2 g}[3]$

$\mathrm{H}_{\mathrm{f}} \quad=0,014 \times \frac{178,5}{0,35} \times \frac{2,21^{2}}{2 \times 9,8}$

$=1,777 \mathrm{~m} \sim 1,78 \mathrm{~m}$

dimana:

$\mathrm{H}_{\mathrm{f}}=$ kehilangan energi sepanjang pipa

$f=$ koefisien gesek pipa $(0,014)$

Ks $=$ koefisien kekasaran pipa baja $(0,045)$

$\mathrm{v}=$ kecepatan pada pipa $(2,21 \mathrm{~m} / \mathrm{dt})$

$\mathrm{g}=$ gravitasi bumi, diambil $9,81 \mathrm{~m} / \mathrm{dt}^{2}$

$\mathrm{D}=$ diameter pipa $(0,35 \mathrm{~m})$

Kehilangan energi total didapat dengan menjumlahkan hasil dari perhitungan dari kehilangan energi akibat saringan kasar, bentuk entrance, dan kehilangan energi akibat gesekan sepanjang pipa. Perhitungan kehilangan energi total sebesar:

$$
\begin{aligned}
\Delta \mathrm{h}_{\text {total }} & =\Delta \mathrm{h}_{\mathrm{r}}+\Delta \mathrm{h}_{\mathrm{e}}+\Delta \mathrm{h}_{\mathrm{f}} \\
& =0,108075+0,012447+1,78 \\
& =1,900522 \sim 1,9 \text { meter }
\end{aligned}
$$

Berdasarkan hasil perhitungan, kehilangan energi total lebih kecil dari asumsi awal 10\% dari tinggi bruto, yaitu 2,77 meter, sehingga perencanaan ini dapat diterima.

\section{F. Perhitumgan Energi Listrik yang Dihasilkan}

Daya yang dihasilkan didapat dari hubungan antara tinggi jatuh efektif, debit rencana, dan percepatan gravitasi, dengan perumusan:

$\mathrm{P}=9,81 \times \mathrm{Q}_{\text {rencana }} \times \mathrm{H}_{\mathrm{eff}}[1]$

Secara garis besar dengan memasukan nilai $Q_{\text {rencanadan }} \mathrm{H}_{\text {eff }}$ langkah-langkah perhitungan daya listrik ditampilkan pada tabel 1 dengan keterangan perhitungan tiap kolom tabel adalah sebagai berikut:
1. Nomor
2. Bulan
3. Periode
4. Jumlah hari tiap periode sepuluh harian
5. Debit inflow PLTA
6. Gaya gravitasi $9,81 \mathrm{~m} / \mathrm{dt}^{2}$
7. Elevasi muka air bendungan (Upstream )
8. Elevasi Muka air Rumah Turbin (Downstream)
9. $\mathrm{H}_{\text {bruto }}$ (selisih el.Upstream - el. Downstream)
10. $\mathrm{H}_{\text {losses }}: 1,9$ meter 
Perencanaan Pembangkit Listrik Tenaga Mikrohidro d i Bendungan Semantok, Nganjuk, Jawa Timur

11. Tinggi jatuh efektih $\mathrm{H}_{e f f}$

12. Daya yang dihasilkan : (5) $\times(6) \times(11)$

13. Energi listrik yang dihasilkan: (12) $\mathrm{x}(24 \mathrm{jam}) \mathrm{x}(4)$

Tabel 1. Perhitungan Daya dan Energi Listrik yang Dihasilkan

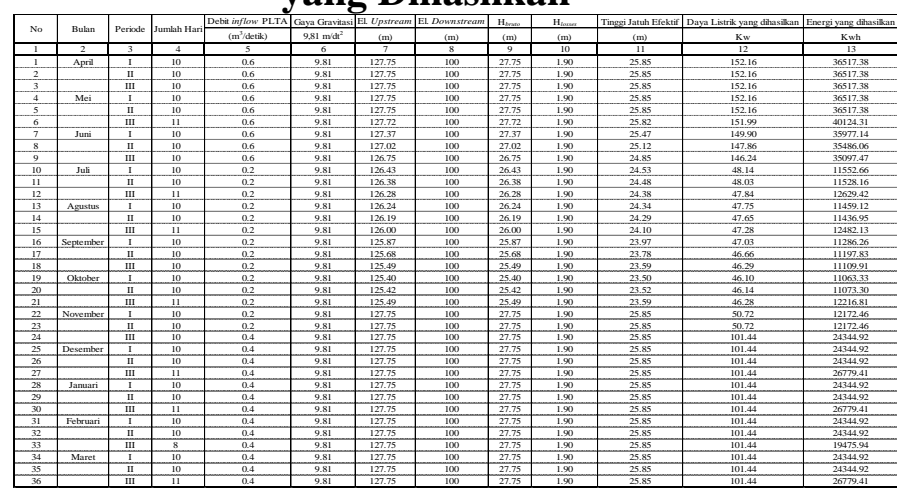

Sumber: Hasil Perhitungan, 2014

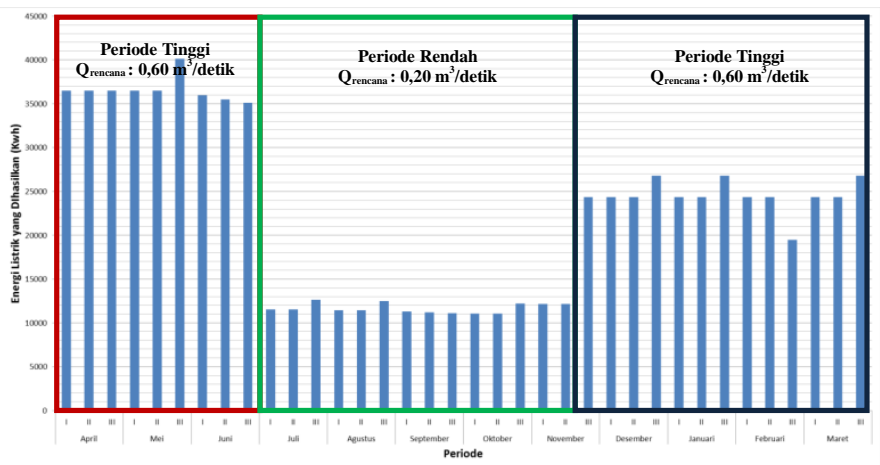

Gambar 6. Grafik Energi yang Dihasilkan

Dari hasil perhitungan pada tabel 1 tentang perhitungan daya dan energi yang dihasilkan, daya yang dihasilkan selama satu tahun adalah sebesar 3342,06 Kw. Dengan daya minimum yang dihasilkan adalah sebesar $46.10 \mathrm{Kw}$ terjadi pada awal bulan Oktober, sedangkan daya maksimum yang dihasilkan adalah sebesar $152,16 \mathrm{Kw}$ terjadi pada awal bulan April sampai hari ke-20 bulan Mei.

Sedangkan energi listrik yang dihasilkan selama satu tahun adalah sebesar 811.571,18 Kwh dengan rata-rata energi yang dihasilkan adalah sebesar 22.543,64 Kwh. Sedangkan energi listrik minimum yang dihasilkan sebesar $11.063,33 \mathrm{Kwh}$ terjadi pada awal bulan oktober dan energi maksimum yang dihasilkan sebesar 40.124,31 Kwh terjadi pada 10 (sepuluh) hari terakhir bulan Mei.

\section{KESIMPULAN}

Pembangunan pembangkit listrik tenaga mikrohidro (PLTMH) merupakan salah satu alternatif untuk memanfaatkan kehilangan energi pada Bendungan Semantok, di Desa Sambikerep, Kecamatan Rejoso, Nganjuk, Jawa Timur. Adapun hasil perencanaan PLTMH pada bendungan Semantok adalah sebagai berikut:

1. Analisa debit

Dari analisa data debit kebutuhan irigasi Daerah Irigasi Bendungan Semantok, didapatkan debit rencana untuk periode tinggi $0,60 \mathrm{~m}^{3} /$ detik, periode sedang 0,40 $\mathrm{m}^{3} /$ detik, dan periode rendah $0,20 \mathrm{~m}^{3} /$ detik.

2. Kehilangan energi

Akibat Saringan Kasar : 0,108075 meter

Akibat entrance : 0,012447 meter

Akibat gesekan sepanjang pipa $: 1,78$ meter

$\Delta \mathrm{h}_{\text {total }}=0,108075+0,012447+1,78$

$=1,9$ meter

3. Perencanaan saluran pembangkit

- Bangunan intake direncanakan bangunan free intake tower. Terletak di sebelah kanan bendungan, berbentuk shaft tegak dari elevasi +119.00 meter sampai elevasi +96.40 meter, dengan lubang pengambilan dari elevasi +116.90 meter sampai elevasi +119.00 meter.

- Saluran pengarah

Diameter saluran $\quad=0,3$ meter

Jumlah Saluran $\quad=3$ buah

Kecepatan Aliran $\quad=2,83 \mathrm{~m} /$ detik

Panjang saluran $=5$ meter

- Pipa pesat Diameter pipa $=0,55$ meter

Panjang saluran $\quad=108$ meter

Kecepatan aliran $\quad=2,07 \mathrm{~m} /$ detik

Tebal pipa $\quad=8 \mathrm{~mm}$

- Turbin

Jenis turbin = Kaplan

Kapasitas $\quad=155,10 \mathrm{Kw}$

4. Daya listrik yang dihasilkan

Daya listrik per tahun : 3.407,79 Kw

Daya listrik rata-rata yang dihasilkan :

$92,80 \mathrm{Kw}$ 
Daya minimum (awal bulan Oktober) : 47,08 Kw

Daya maksimum (awal bulan April) : $155,10 \mathrm{Kw}$

5. Energi listrik yang dihasilkan

Energi listrik per tahun

: 827.534,01Kwh

Rata-rata energi yang dihasilkan : 22.987,06 Kwh

Energi Minimum (awal bulan Oktober) : 11.298,77 Kwh
Energi Maksimum (akhir bulan Mei) : 40.901,27 Kwh

\section{DAFTAR PUSTAKA}

[1] Patty, O.F. 1995. “Tenaga Air”. Jakarta. Erlangga.

[2] Anggrahini. 1997. "Hidrolika Saluran Terbuka”. Surabaya. CV. Citra Media.

[3] Varsney, R.S. 1997. "Hydro Power Structure". $2^{\text {nd }}$ Edition. New Chand \& Brosoorke. 